\title{
Critical Involvement of cAMP/DARPP-32 and Extracellular Signal-Regulated Protein Kinase Signaling in L-DOPA-Induced Dyskinesia
}

\author{
Emanuela Santini, ${ }^{1}$ Emmanuel Valjent, ${ }^{2,3,4}$ Alessandro Usiello, ${ }^{5}$ Manolo Carta, ${ }^{6}$ Anders Borgkvist, ${ }^{1}$ \\ Jean-Antoine Girault, ${ }^{2,3,4}$ Denis Hervé, ${ }^{2,3,4}$ Paul Greengard, ${ }^{7}$ and Gilberto Fisone ${ }^{1,7}$ \\ ${ }^{1}$ Department of Neuroscience, Karolinska Institutet, 17177 Stockholm, Sweden, ${ }^{2}$ Inserm, Unité 839, 75005 Paris, France, ${ }^{3}$ Université Pierre et Marie Curie, \\ 75005 Paris, France, ${ }^{4}$ Institut du Fer à Moulin, 75005 Paris, France, ${ }^{5}$ Centro di Ingegneria Genetica, Biotecnologie Avanzate, 80145 Naples, Italy, \\ ${ }^{6}$ Wallenberg Neuroscience Centre, Lund University, 22184 Lund, Sweden, and 7 Laboratory of Molecular and Cellular Neuroscience, The Rockefeller \\ University, New York, New York 10021
}

The molecular basis of L-3,4-dihydroxyphenylalanine (L-DOPA)-induced dyskinesia (LID), one of the major hindrances in the current therapy for Parkinson's disease, is still unclear. We show that attenuation of cAMP signaling in the medium spiny neurons of the striatum, achieved by genetic inactivation of the dopamine and cAMP-regulated phosphoprotein of $32 \mathrm{kDa}$ (DARPP-32), reduces LID. We also show that, in dyskinetic mice, sensitized cAMP/cAMP-dependent protein kinase/DARPP-32 signaling leads to phosphorylation/activation of the extracellular signal-regulated protein kinases 1 and 2 (ERK1/2). The increase in ERK1/2 phosphorylation associated with dyskinesia results in activation of mitogen- and stress-activated kinase-1 (MSK-1) and phosphorylation of histone H3, two downstream targets of ERK involved in transcriptional regulation. In line with these observations, we found that c-Fos expression is abnormally elevated in the striata of mice affected by LID. Persistent enhancement of the ERK signaling cascade is implicated in the generation of LID. Thus, pharmacological inactivation of ERK1/2 achieved using SL327 ( $\alpha$-[amino[(4-aminophenyl)thio]methylene]-2-(trifluoromethyl)benzeneacetonitrile), an inhibitor of the mitogen-activated kinase/ERK kinase, MEK, during chronic L-DOPA treatment counteracts the induction dyskinesia. Together, these results indicate that a significant proportion of the abnormal involuntary movements developed in response to chronic L-DOPA are attributable to hyperactivation in striatal medium spiny neurons of a signaling pathway including sequential phosphorylation of DARPP-32, ERK1/2, MSK-1, and histone $\mathrm{H} 3$.

Key words: mouse; MSK-1; 6-OHDA; Parkinson's disease; SL327; striatum

\section{Introduction}

The abnormal involuntary movements (AIMs), or dyskinesia, that develop in response to prolonged administration of L-3,4dihydroxyphenylalanine (L-DOPA) represent one of the major challenges to the existing therapy for Parkinson's disease. These severe motor side effects have been associated with changes affecting dopaminergic and glutamatergic transmission in the medium spiny neurons of the striatum (Brotchie et al., 2005). Studies performed in 1-methyl-4-phenyl-1,2,3,6-tetrahydropyridine (MPTP)-lesioned monkeys show that L-DOPA-induced dyskinesia (LID) appears concomitantly with augmented coupling of striatal dopamine $\mathrm{D}_{1}$ receptors to G-protein (Aubert et al., 2005).

Received Feb. 26, 2007; revised April 27, 2007; accepted May 15, 2007.

This work was supported by Swedish Research Council Grants 13482 and 14862 and the Björn Oscarssons donation (G.F.), The Peter Jay Sharp Foundation, The Picower Foundation and National Institutes of Health Grants MH40899 and DA10044 (P.G.), Inserm and Fondation de la Recherche Médicale (E.V., D.H., and J.-A.G.), and Grant ANR-05-NEUR-020-03 from Agence Nationale de la Recherche (J.-A.G.). A.U. was a recipient of a fellowship from the Wenner-Gren Foundations.

Correspondence should be addressed to Gilberto Fisone, Department of Neuroscience, Karolinska Institutet, Retzius väg 8, 17177 Stockholm, Sweden. E-mail: gilberto.fisone@ki.se.

DOI:10.1523/JNEUROSCI.0852-07.2007

Copyright $\odot 2007$ Society for Neuroscience $\quad$ 0270-6474/07/276995-11\$15.00/0
In addition, it has been reported that the striata of dopaminedepleted rats or parkinsonian patients contain higher levels of $\mathrm{G}_{\text {olf }}$ and that this leads to an enhancement of dopaminestimulated cAMP production (Corvol et al., 2004).

The occurrence of exaggerated dopamine $\mathrm{D}_{1}$ receptor transmission in LID is reflected in an altered state of phosphorylation of the dopamine- and cAMP-dependent phosphoprotein of 32 $\mathrm{kDa}$ (DARPP-32), which is selectively expressed in medium spiny neurons. Activation of dopamine $\mathrm{D}_{1}$ receptors increases cAMP production via $\mathrm{G}_{\mathrm{olf}}$-mediated stimulation of adenylyl cyclase (Zhuang et al., 2000; Corvol et al., 2001). This leads to enhanced phosphorylation of DARPP-32 at Thr34, a site specifically regulated by cAMP-dependent protein kinase (PKA) (Nishi et al., 1997; Svenningsson et al., 2000). Thus, abnormally high levels of phospho-Thr34-DARPP-32 have been found in the striata of dyskinetic rats (Picconi et al., 2003).

PKA-catalyzed phosphorylation at Thr34 converts DARPP-32 into an inhibitor of protein phosphatase-1 (PP-1) (Hemmings et al., 1984), thereby suppressing dephosphorylation of downstream target proteins involved in the control of the activity of striatal medium spiny neurons. In this way, the cAMP/PKA/ DARPP-32/PP-1 cascade represents an important mechanism of 
amplification able to intensify behavioral responses produced by activation of dopamine $\mathrm{D}_{1}$ receptors (Fienberg et al., 1998).

Recent work has demonstrated the importance of phosphoThr34-DARPP-32 in the regulation of extracellular signalregulated kinases 1 and 2 (ERK1/2) (Valjent et al., 2005), two mitogen-activated kinases involved in neuronal transmission and synaptic plasticity (Sweatt, 2004; Thomas and Huganir, 2004). In particular, it has been proposed that phospho-Thr34DARPP-32 acts by promoting phosphorylation of ERK, via activation of the mitogen-activated protein kinase/ERK kinase (MEK), and by inhibiting ERK dephosphorylation, via inhibition of the striatal-enriched phosphatase STEP (Valjent et al., 2005). DARPP-32-dependent phosphorylation of ERK1/2 has been shown to participate in the development of psychomotor sensitization induced by dopaminomimetic drugs, such as cocaine and amphetamine (Valjent et al., 2005). The possibility of an involvement of ERK in L-DOPA-mediated motor disturbances is suggested by recent studies showing that, in 6-hydroxydopamine-lesioned mice, chronic administration of L-DOPA is accompanied by enhanced levels of phosphorylated ERK (Pavon et al., 2006).

Despite these various studies, evidence in support of the participation of the cAMP/PKA/DARPP-32 and ERK1/2 pathways in the generation of LID is still lacking. In this study, we made use of a mouse model of LID (Lundblad et al., 2004; Lundblad et al., 2005) to demonstrate that dysregulation of cAMP/PKA/ DARPP-32 signaling mediates the increase in phosphorylation of ERK1/2 associated with AIMs and that genetic or pharmacological attenuation of cAMP/PKA/DARPP-32 and/or ERK signaling counteracts dyskinesia.

\section{Materials and Methods}

Animals. Male C57BL/6 mice (30 g) were purchased from Charles River Laboratories (Sulzfeld, Germany). Male wild-type and DARPP-32 knock-out mice (Fienberg et al., 1998) were generated from the offspring of DARPP $-32^{+/+} \times D A R P P-32^{+/+}$and DARPP- $32^{-/-} \times D A R P P-32^{-/-}$ mating pairs, which were backcrossed for at least 20 generations on a C57BL/6 background. DARPP- $32^{+/+} \times D A R P P-32^{+/+}$and DARPP$32^{-/-} \times D A R P P-32^{-1-}$ mating was performed separately for no more than two generations. All of the studies were performed in accordance with the Swedish Animal Welfare Agency.

Drugs. All drugs were injected intraperitoneally in a volume of 10 $\mathrm{ml} / \mathrm{kg}$ of body weight. L-DOPA (methyl-L-DOPA hydrochloride; $20 \mathrm{mg} /$ $\mathrm{kg}$ ) and the peripheral DOPA decarboxylase inhibitor benserazide hydrochloride $(12 \mathrm{mg} / \mathrm{kg}$ ) (Sigma, Stockholm, Sweden) were dissolved in physiological saline immediately before use. SL327 ( $\alpha$-[amino[(4aminophenyl)thio]methylene]-2-(trifluoromethyl)benzeneacetonitrile) (75 mg/kg), a gift from Dr. Edilio Borroni (Hoffmann-La Roche, Basel, Switzerland), was suspended by sonication in a solution of $5 \%$ Tween 80 in saline and administered $45 \mathrm{~min}$ before injection of L-DOPA. When mice were not treated with drugs, they received equivalent volumes of vehicles.

6-OHDA lesion. Mice were anesthetized with a mixture of fentanyl citrate $(0.315 \mathrm{mg} / \mathrm{ml})$, fluanisone $(10 \mathrm{mg} / \mathrm{ml})$ (VetaPharma, Leeds, UK), midazolam (5 mg/ml) (Hameln Pharmaceuticals, Gloucester, UK), and water (1:1:2; in a volume of $2.7 \mathrm{ml} / \mathrm{kg})$ and mounted in a stereotactic frame (David Kopf Instruments, Tujunga, CA) equipped with a mouseadaptor. 6-OHDA-HCl (Sigma) was dissolved in $0.02 \%$ ascorbic acid in saline at the concentration of $3.0 \mu \mathrm{g}$ of freebase 6-OHDA/ $\mu \mathrm{l}$. Mice received unilateral injections $(2 \times 2 \mu \mathrm{l})$ of vehicle or 6-OHDA into the right striatum at the following coordinates according to the mouse brain atlas (Paxinos and Watson, 1982): anteroposterior $+1.0 \mathrm{~mm}$, mediolateral $-2.1 \mathrm{~mm}$, dorsoventral $-3.2 \mathrm{~mm}$; and anteroposterior $+0.3 \mathrm{~mm}$, mediolateral $-2.3 \mathrm{~mm}$, dorsoventral -3.2 . Each injection was performed at a rate of $0.5 \mu \mathrm{l} / \mathrm{min}$ using a glass capillary with an outer diameter of $\sim 50 \mu \mathrm{m}$ attached to a $10 \mu \mathrm{l}$ Hamilton syringe. After the injection, the capillary was left in place for an additional 3 min before slowly re- tracting it (Lundblad et al., 2005). Mice were allowed to recover for 4 weeks, before behavioral evaluation and drug treatment. Lesions were assessed at the end of the experiments by determining the striatal levels of tyrosine hydroxylase (TH) using Western blotting (see below).

Cylinder test. The cylinder test (Schallert and Tillerson, 2000) was used to monitor the anti-akinetic effect of L-DOPA. Mice were placed in individual glass cylinders (diameter, $12 \mathrm{~cm}$ ) and were recorded for $5 \mathrm{~min}$. Each 6-OHDA-lesioned mouse was tested before the beginning of $\mathrm{L}$-DOPA therapy and $1 \mathrm{~h}$ after the first injection of L-DOPA plus benserazide. Sham-lesioned mice were used as control. The number of wall contacts with the right and the left forelimb were counted by an observer blind to mouse genotype and drug treatment. To discriminate between accidental touches and meaningful physiological movements, only wall contacts where the animal supported its body weight on the paw with extended digits were counted. The use of the impaired (left) forelimb was expressed as a percentage of the total number of supporting wall contacts.

Turning behavior. 6-OHDA-lesioned mice were treated with L-DOPA $(20 \mathrm{mg} / \mathrm{kg})$ plus benserazide $(12 \mathrm{mg} / \mathrm{kg})$ or with a combination of these drugs plus SL327 $(75 \mathrm{mg} / \mathrm{kg})$. The animals were immediately placed in individual glass cylinders (diameter of $12 \mathrm{~cm}$ ), and their motor activity was recorded over $1 \mathrm{~h}$. The number of ipsilateral and contralateral rotations was determined by an observer blind to mouse treatment.

AIMs. 6-OHDA-lesioned wild-type and DARPP-32 knock-out mice were treated for $10 \mathrm{~d}$ with one injection per day of L-DOPA $(20 \mathrm{mg} / \mathrm{kg})$ plus benserazide $(12 \mathrm{mg} / \mathrm{kg})$. The effect of SL327 was examined by treating 6-OHDA-lesioned mice for $9 \mathrm{~d}$ with L-DOPA/benserazide plus SL327 and, on day 10, by administering L-DOPA alone or in combination with SL327. AIMs were assessed after the last injection of L-DOPA (day 10) by an observer blind to mouse genotype and treatment, using a previously established and validated mouse model of LID (Lundblad et al., 2004; Lundblad et al., 2005). Twenty minutes after L-DOPA administration, mice were placed in separate cages and individual dyskinetic behaviors were assessed for $1 \mathrm{~min}$ (monitoring period) every $20 \mathrm{~min}$, over a period of $140 \mathrm{~min}$. Purposeless movements, clearly distinguished from natural stereotyped behaviors (i.e., grooming, sniffing, rearing, and gnawing), were classified into four different subtypes: locomotive AIMs (tight contralateral turns), axial AIMs (contralateral dystonic posture of the neck and upper body toward the side contralateral to the lesion), limb AIMs (jerky and fluttering movements of the limb contralateral to the side of the lesion), and orolingual AIMs (vacuous jaw movements and tongue protrusions). Each subtype was scored on a severity scale from 0 to 4: 0 , absent; 1 , occasional; 2 , frequent; 3 , continuous; 4 , continuous and not interruptible by outer stimuli.

Western blotting. Twenty-four hours after AIM assessment, the mice were treated with various combinations of vehicle, L-DOPA/benserazide, and SL327, as described and killed by decapitation $30 \mathrm{~min}$ later. The heads of the animals were immediately immersed in liquid nitrogen for $6 \mathrm{~s}$. The brains were then removed and the striata were dissected out within $20 \mathrm{~s}$ on an ice-cold surface, sonicated in $750 \mu \mathrm{l}$ of $1 \%$ SDS, and boiled for $10 \mathrm{~min}$. The effectiveness of this extraction procedure in preventing protein phosphorylation and dephosphorylation, hence ensuring that the level of phosphoproteins measured ex vivo reflects the in vivo situation, has been tested previously (Svenningsson et al., 2000). Aliquots $(5 \mu \mathrm{l})$ of the homogenate were used for protein determination using a BCA assay kit (Pierce Europe, Oud Beijerland, The Netherlands). Equal amounts of protein $(30 \mu \mathrm{g})$ for each sample were loaded onto $10 \%$ polyacrylamide gels. Proteins were separated by SDS-PAGE and transferred overnight to polyvinylidene difluoride membranes (GE Healthcare, Little Chalfont, UK) (Towbin et al., 1979). The membranes were immunoblotted using phospho-Ser845-glutamate AMPA receptor subunit 1 (GluR1), phospho-Ser831-GluR1 (Upstate Biotechnology, Lake Placid, NY), phospho-Thr202/Tyr204-ERK1/2 (Cell Signaling Technology, Beverly, MA), and phospho-Thr34-DARPP-32 (Snyder et al., 1992) antibodies. Antibodies against GluR1 (Upstate Biotechnology), ERK1/2 (Cell Signaling Technology), and DARPP-32 (Hemmings and Greengard, 1986) that are not phosphorylation state specific were used to estimate the total amount of proteins. Antibody against TH (Chemicon, Temecula, CA) was used to assess the severity of the 6-OHDA lesions. Detection was based on fluorescent secondary antibody binding detected 
and quantitated using a LI-COR (Lincoln, NE) Odyssey infrared fluorescent detection system. The levels of each phosphoprotein were normalized for the amount of the corresponding total protein detected in the sample.

Tissue preparation and immunofluorescence staining. Twenty-four hours after AIM assessment, the mice were treated with various combinations of vehicle, L-DOPA/benserazide, and SL327, as described. Thirty minutes after drug administration, the animals were rapidly anesthetized with pentobarbital (30 mg/kg, i.p.; Sanofi-Aventis, Paris, France) and perfused transcardially with a fixative solution containing $4 \%$ paraformaldehyde (wt/vol) in PBS, pH 7.5. Brains were postfixed overnight in the same solution and stored at $4^{\circ} \mathrm{C}$. Sections $(30-\mu \mathrm{m}$-thick) were cut with a vibratome (Leica, Nussloch, Germany) and kept at $-20^{\circ} \mathrm{C}$ in a solution containing 30\% ethylene glycol (vol/vol), 30\% glycerol (vol/ vol), and $0.1 \mathrm{M}$ phosphate buffer. For detection of phosphorylated proteins, $50 \mathrm{~mm} \mathrm{NaF}$ was included in all buffers and incubation solutions, as described previously (Valjent et al., 2005). Immunolabeling was performed as described previously (Valjent et al., 2005), using Alexa 488- or cyanine 3-coupled secondary antibodies (Invitrogen, Leiden, The Netherlands). Sections were mounted in Vectashield with 4', 6' -diamidino-2phenylindole counterstain (Vector Laboratories, Paris, France). Active ERK was detected with rabbit polyclonal antibodies against diphosphoERK1/2 (1:400; Cell Signaling Technology) or, when necessary for double-labeling, with monoclonal anti-phospho-ERK1/2 (1:200; Sigma). The other antibodies were rabbit polyclonal antibodies against the following: phospho-Thr581-mitogen- and stress-activated kinase-1 (MSK-1) (1:750; Cell Signaling Technology), phospho-Ser10-histone H3 (1:1000), phospho-Ser10-acetylLys14 histone H3 (1:500; Upstate Biotechnology), c-Fos (1:1000; Sc52; Santa Cruz Biotechnology, Santa Cruz, CA), and a mouse monoclonal antibody against DARPP-32 (1: 2000) (Snyder et al., 1992). Images were captured using sequential laser scanning confocal microscopy (SP2; Leica) and analyzed using MetaMorph software (Universal Imaging, Downingtown, PA). Quantification was performed by counting the number of cells with nuclear fluorescence above background using a MetaMorph analyzer, in two brain sections per animal in the dorsal striatum.

Statistics. Biochemical data were analyzed using one-way or two-way ANOVA, in which treatment and genotype were the independent variables, followed by Bonferroni-Dunn post hoc test, for specific comparisons. Correlations between variables were estimated using simple regression analysis. Percentages of wall contacts performed with the left forepaw in the cylinder test were compared using one-way ANOVA, in which treatment was the independent variable. AIM scores were compared using repeated-measure ANOVA, in which genotype or treatment and time were the independent variables. Comparisons between sums of total AIMs in low dyskinetic and high dyskinetic mice were performed using Student's $t$ test.

\section{Results \\ Effects of acute and repeated administration of L-DOPA in 6-OHDA-lesioned mice}

Injection of 6-OHDA in the striata of $\mathrm{C} 57 \mathrm{BL} / 6$ mice reduced $\mathrm{TH}$ immunoreactivity to $9.5 \pm 1.1 \%$ of control sham-lesioned animals. Four weeks after surgery, sham- and 6-OHDA-lesioned mice were examined in the cylinder test to estimate the degree of motor impairment produced by dopamine denervation. Shamlesioned animals showed similar usage of left and right forelimb in wall contacts. In contrast, mice injected with 6-OHDA displayed a dramatic reduction in the use of the left forelimb, i.e., the forelimb contralateral to the side of the 6-OHDA lesion. Administration of L-DOPA $(20 \mathrm{mg} / \mathrm{kg}$ in combination with $12 \mathrm{mg} / \mathrm{kg}$ benserazide) produced a complete recovery in the use of the left forelimb (Fig. 1a). Mice were then treated daily with L-DOPA (20 $\mathrm{mg} / \mathrm{kg}$ ) plus benserazide $(12 \mathrm{mg} / \mathrm{kg})$, and AIMs were determined $10 \mathrm{~d}$ later. The duration of drug administration was based on previous studies showing that, in the mouse, AIMs are maximally expressed during the second week of L-DOPA treatment (Lund- blad et al., 2005). The time course of locomotive, axial, limb, and orolingual AIMs was determined immediately after administration of L-DOPA. AIMs were maximal at $20 \mathrm{~min}$ after L-DOPA administration, declined after $80 \mathrm{~min}$, and disappeared after 140 min (Fig. 1b). All individual AIMs developed with an identical time course (data not shown). In general, mice displayed a wide range of AIM severity, with only few animals being completely nondyskinetic. This is most likely attributable to the fact that this study was limited to mice with a severe reduction of striatal $\mathrm{TH}$ (see below). In parkinsonian patients, progressive depletion of striatal dopamine is generally regarded as an important factor contributing to the development of LID (Obeso et al., 2000). For this reason, only mice with a decrease in striatal $\mathrm{TH}$ immunoreactivity $\geq 80 \%$ were included in the study. In these animals, we did not observe any correlation between reduction of $\mathrm{TH}$ and severity of AIMs (Fig. 1c). Thus, changes in signaling later identified in the study could be unequivocally associated with the degree of dyskinetic behavior rather than with the extent of dopamine denervation.

\section{Increased phosphorylation of DARPP-32 at Thr34 and GluR1 AMPA receptor at Ser845 are associated with LID}

An association between increased phosphorylation of DARPP-32 at Thr34 and dyskinesia has been established using a rat model of LID (Picconi et al., 2003). We therefore examined whether a similar abnormal phosphorylation of DARPP-32 also occurred in dyskinetic mice. Lesion with 6-OHDA per se did not alter the state of phosphorylation of DARPP-32 at Thr34, nor did it affect the state of phosphorylation of another PKA target, the GluR1 subunit of the glutamate AMPA receptor (data not shown). Similarly, administration of L-DOPA to sham-lesioned mice did not change the state of phosphorylation of DARPP-32 or GluR1 (Fig. $2 a, c)$. In contrast, acute administration of L-DOPA $(20 \mathrm{mg} / \mathrm{kg})$ to 6-OHDA-lesioned mice resulted in a dramatic increase in the state of phosphorylation of DARPP-32 at Thr34 (Fig. 2a) and of GluR1 at the PKA site Ser845 (Roche et al., 1996) (Fig. 2c). These results indicate that dopamine depletion is accompanied by a considerable increase in dopamine $\mathrm{D}_{1}$ receptor responsiveness at the postsynaptic level. This sensitized response appears to involve specifically PKA-mediated signaling, as suggested by unaltered phosphorylation of GluR1 at Ser831, a calcium/calmodulin protein kinase II and protein kinase C site (Roche et al., 1996; Mammen et al., 1997) (data not shown). Repeated administration of L-DOPA (20 mg/kg for $10 \mathrm{~d}$ ) to 6-OHDA-lesioned mice resulted in an overall attenuation of the ability of this drug to increase PKA-mediated phosphorylation of DARPP-32 and GluR1 (Fig. $2 a, c)$. However, when mice chronically treated with L-DOPA were divided into low and highly dyskinetic according to their AIM score, we found significantly higher levels of phosphoDARPP-32 and phospho-GluR1 in the highly dyskinetic group (Fig. 2a,c). In line with these findings, simple regression analysis revealed the existence of a correlation between severity of AIMs and levels of phosphorylated DARPP-32 (Fig. 2b) and GluR1 (Fig. $2 d$ ). Total levels of DARPP-32 and GluR1 were unaffected by 6-OHDA lesion and/or treatment with L-DOPA (data not shown).

\section{LID is associated with hyperphosphorylation of ERK1/2}

Phospho-Thr34-DARPP-32 has been shown to promote ERK phosphorylation (Valjent et al., 2005). Moreover, in 6-OHDAlesioned mice, chronic treatment with L-DOPA results in elevated ERK phosphorylation (Pavon et al., 2006). We therefore examined the possibility that changes in phosphorylation of ERK1/2 
a

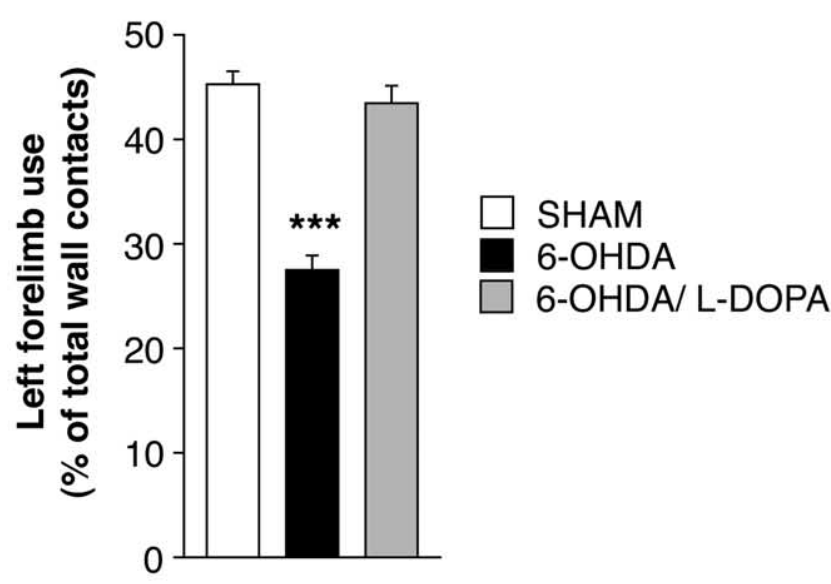

b

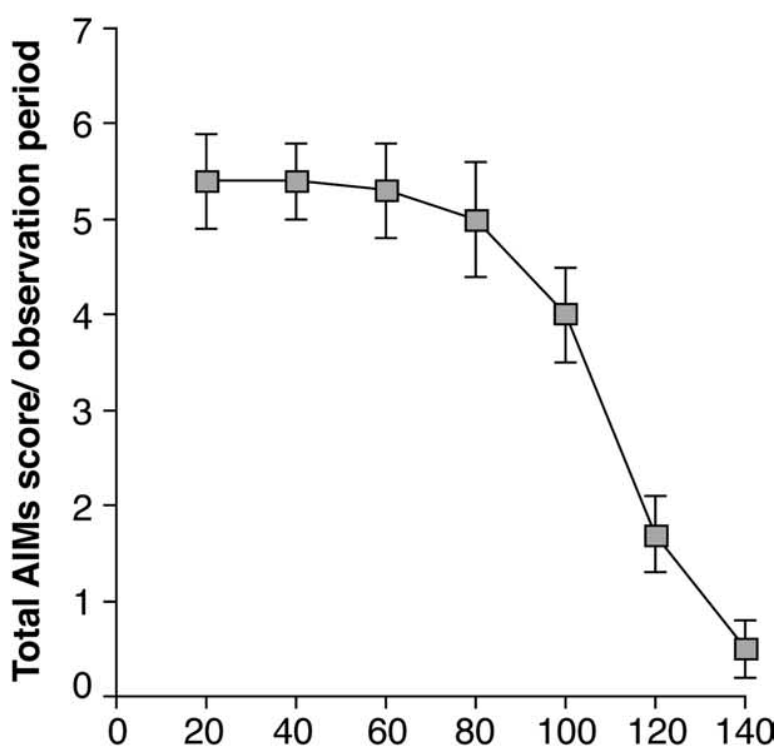

Time after L-DOPA injection ( $\mathrm{min})$

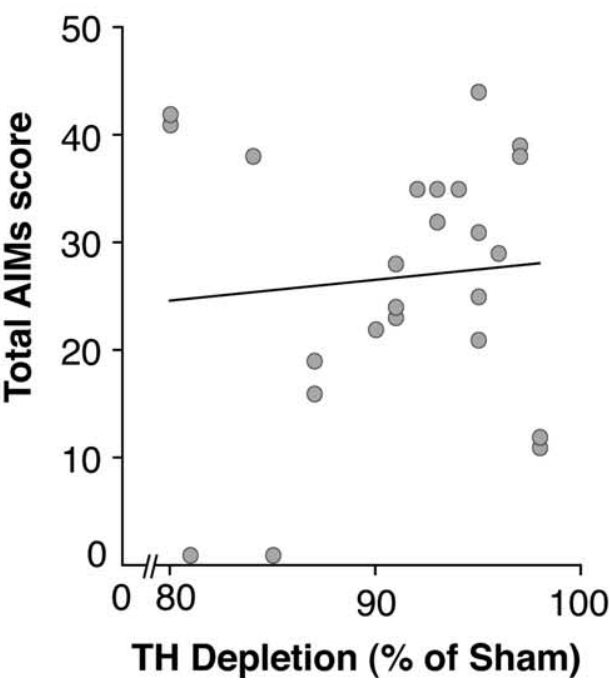

$\square$ Saline

L-DOPA Acute

L-DOPA Chronic

a
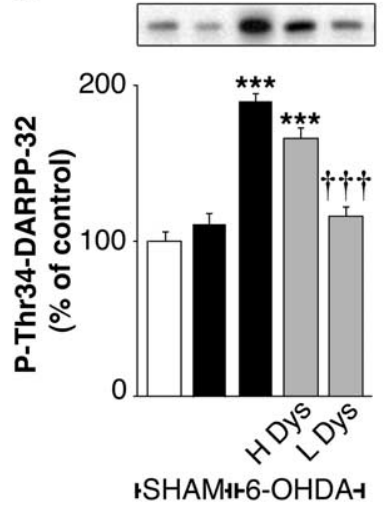

C
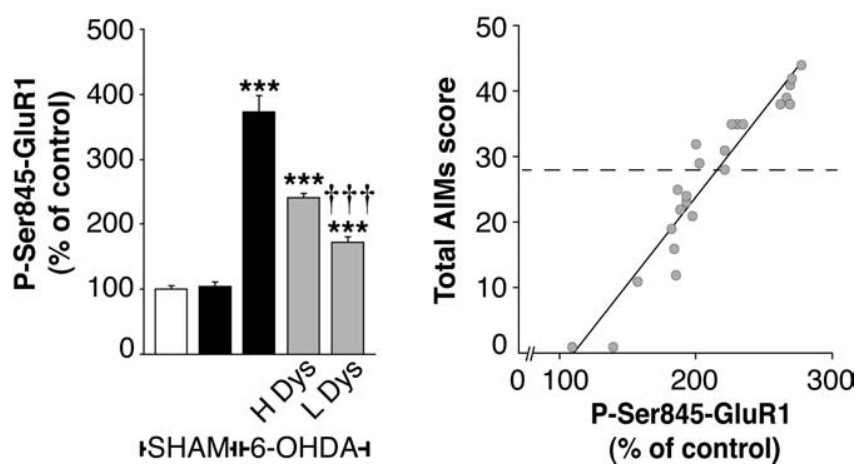

Figure 2. PKA-mediated phosphorylation of DARPP-32 and GluR1 is associated with LID. Sham- or 6-OHDA-lesioned mice were treated with saline, acute L-DOPA, or chronic L-DOPA. Phospho-Thr34-DARPP-32 $(\boldsymbol{a}, \boldsymbol{b})$ and phospho-Ser845-GluR1 $(\boldsymbol{c}, \boldsymbol{d})$ were determined by Western blotting (see Materials and Methods). $\boldsymbol{a}, \boldsymbol{c}, 6-0 \mathrm{HDA}$-lesioned mice were divided into low dyskinetic (L Dys) and highly dyskinetic (H Dys) according to their total AIM score (see Materials and Methods) using the median value of 28 as cutoff. Top row shows representative autoradiograms. Bottom row is a summary of data represented as means \pm SEM $(n=9-13)$. ${ }^{* * *} p<0.001$ versus Sham treated with saline; ${ }^{+t+} p<0.001$ versus H Dys; one-way ANOVA ( $\boldsymbol{a}$, $\left.F_{(4,52)}=38.44 ; \boldsymbol{b}, F_{(4,52)}=69.85\right)$, followed by Bonferroni-Dunn test. $\boldsymbol{b}$, $\boldsymbol{d}$, Simple regression analysis indicating a significant correlation between AIMs and levels of phospho-Thr34DARPP-32 $(\boldsymbol{b})(r=0.921 ; p<0.001)$ and phospho-Ser845-GluR1 $(\boldsymbol{d})(r=0.953 ; p<0.001)$.

were associated with AIM severity. L-DOPA did not affect ERK1/2 phosphorylation in naive mice but produced a large increase in phospho-ERK1/2 when given to 6-OHDA-lesioned mice (Fig. $3 a, c, e$ ). This effect was attenuated after repeated administration of L-DOPA but remained more pronounced in highly dyskinetic mice compared with low dyskinetic mice (Fig. $3 a, c, e)$. Simple regression analysis revealed a significant correla-

Figure 1. Effects of 6-OHDA lesion and L-DOPA administration. $\boldsymbol{a}$, Left forelimb use was determined using the cylinder test (see Materials and Methods) in sham-lesioned mice (Sham) and in 6-OHDA-lesioned mice before (6-OHDA) or after (6-OHDA/L-DOPA) administration of 20 $\mathrm{mg} / \mathrm{kg} \mathrm{L}-\mathrm{DOPA}$ plus $12 \mathrm{mg} / \mathrm{kg}$ benserazide. Data are means \pm SEM $(n=9-36) .{ }^{* * *} p<0.001$ versus Sham and 6-OHDA/L-DOPA, one-way ANOVA $\left(F_{(1,83)}=37.48\right)$, followed by BonferroniDunn test. $\boldsymbol{b}, 6-0$ HDA-lesioned mice were treated for $10 \mathrm{~d}$ with $20 \mathrm{mg} / \mathrm{kg} \mathrm{L-DOPA} \mathrm{plus} 12 \mathrm{mg} / \mathrm{kg}$ benserazide and total axial, limb, orolingual, and locomotive AIMs were scored every $20 \mathrm{~min}$ over a period of $140 \mathrm{~min}$ after the last drug administration. c, Simple linear regression analysis showing absence of correlation between depletion of TH and AIMs score in 6-OHDA-lesioned mice with a reduction in $\mathrm{TH}$ immunoreactivity $\geq 80 \%(r=0.219 ; p=0.304)$. 


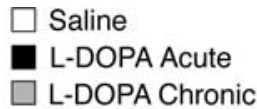

a

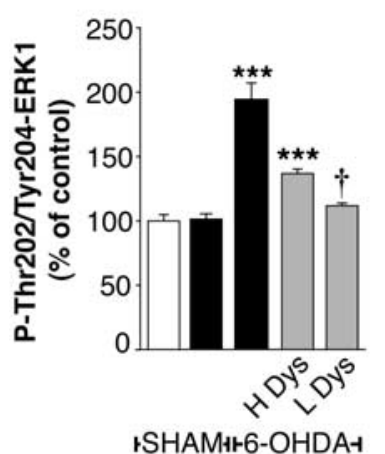

C
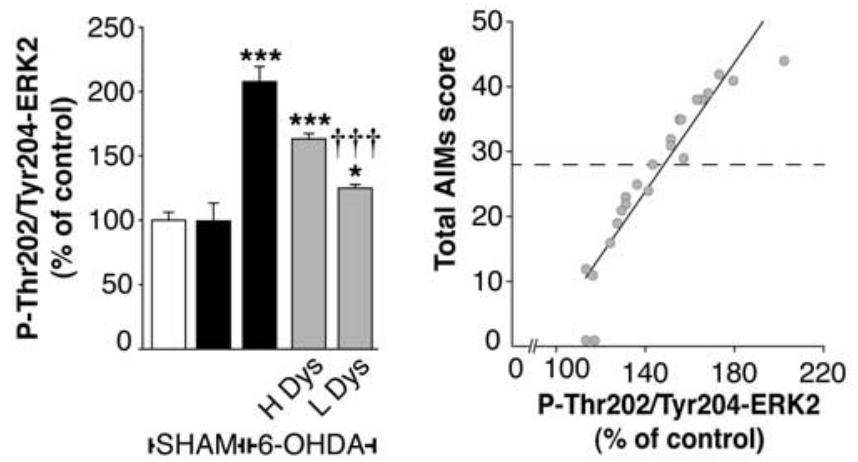

e
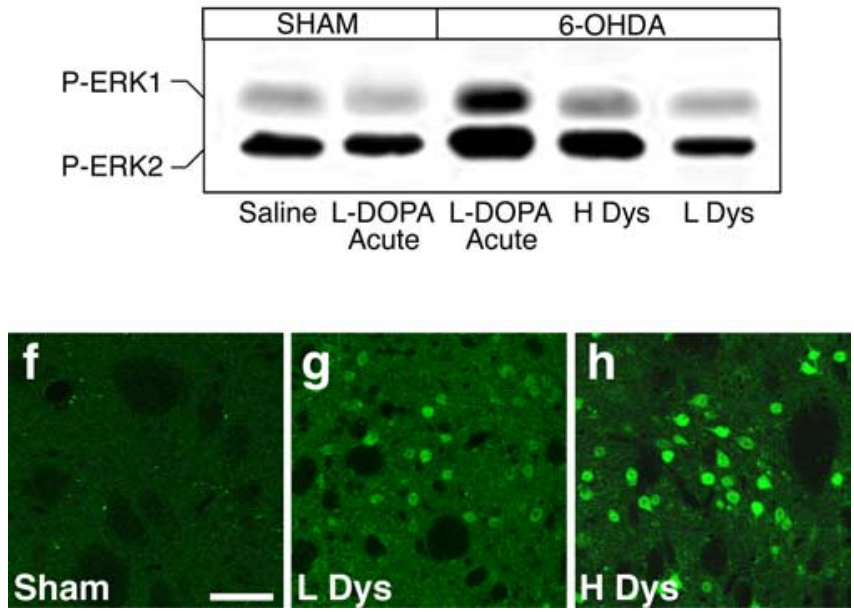

Figure 3. Phosphorylation of ERK1/2 is associated with LID. Sham- or 6-OHDA-lesioned mice were treated with saline, acute L-DOPA, or chronic L-DOPA. Phospho-Thr202/Tyr204-ERK1 ( $\boldsymbol{a}$, $\boldsymbol{b}, \boldsymbol{e}$ ) and ERK2 ( $(\boldsymbol{c} \boldsymbol{e})$ were determined by Western blotting (see Materials and Methods). $\boldsymbol{a}, \boldsymbol{c}$, 6-OHDA-lesioned mice were divided into low dyskinetic (L Dys) and high dyskinetic (H Dys) according to their total AIM score (see Materials and Methods) using the median value of 28 as cutoff. Data are means \pm SEM $(n=9-13) .{ }^{* * *} p<0.001$ versus Sham treated with saline; ${ }^{+t \dagger} p<0.001$ and ${ }^{\dagger} p<0.05$ versus $\mathrm{H}$ Dys; one-way ANOVA $\left(\boldsymbol{a}, F_{(4,52)}=31.64 ; \boldsymbol{c}, F_{(4,52)}=\right.$ 26.96), followed by Bonferroni-Dunn test. $\boldsymbol{b}, \boldsymbol{d}$, Simple regression analysis indicating a significant correlation between AIMs and levels of phospho-Thr202/Tyr204-ERK1 (b) $(r=$ $0.917 ; p<0.001)$ and phospho-Thr202/Tyr204-ERK2 (d) $(r=0.931 ; p<0.001) . e$, Representative autoradiogram showing phospho-ERK1 (P-ERK1) and phospho-ERK2 (P-ERK2) tion between increased ERK1/2 phosphorylation and AIM score (Fig. 3b,d). Immunohistochemical analysis supported these results (Fig. $3 f-h$ ). A significant correlation was found between the number of phospho-ERK-immunopositive neurons and AIMs $(r=0.893 ; p<0.01)$. Phospho-ERK immunoreactivity was colocalized with DARPP-32 immunoreactivity, confirming that abnormal regulation of ERK occurs at the level of medium spiny neurons (supplemental Fig. 1, available at www.jneurosci.org as supplemental material). Total levels of ERK1/2 were unaffected by 6-OHDA lesion and/or treatment with L-DOPA (data not shown).

\section{LID is attenuated in DARPP-32-null mice}

Based on the positive correlation between phosphorylation of DARPP-32 and AIMs, we proceeded to examine the possible involvement of DARPP-32 in LID. DARPP-32 knock-out and wildtype mice received unilateral injections of 6-OHDA. Overall, we observed, in the two genotypes, a comparable degree of dopamine denervation (TH immunoreactivity was decreased to $12.9 \pm 1.4$ and $13.6 \pm 0.9 \%$ of control in wild-type and DARPP-32 knock-out mice, respectively) and motor impairment (percentage use of left forelimb was decreased to $22.5 \pm 1.7$ and $23.2 \pm 1.0 \%$ of total wall contacts in wild-type and DARPP-32 knock-out mice, respectively). Administration of L-DOPA (20 $\mathrm{mg} / \mathrm{kg}$ in combination with $12 \mathrm{mg} / \mathrm{kg}$ benserazide) produced a complete recovery in the use of the left forelimb. No difference in the efficacy of L-DOPA was observed between wild-type and DARPP-32 knock-out mice (percentage use of left forelimb returned to $47.9 \pm 1.1$ and $46.7 \pm 0.6 \%$ of total wall contacts in wild-type and DARPP-32 knock-out mice, respectively). Repeated administration of L-DOPA $(20 \mathrm{mg} / \mathrm{kg}$ daily for $10 \mathrm{~d})$ produced dyskinesia in wild-type and DARPP-32 knock-out mice. However, AIM score was significantly lower in DARPP-32 knock-out mice compared with wild-type mice (Fig. 4a). This decrease was attributable to a marked reduction of axial, limb, and orolingual AIMs (Fig. 4b). In contrast, no difference was observed in the ability of the two strains of mice to express locomotive AIMs in response to chronic L-DOPA treatment (Fig. 4c).

\section{LID-associated phosphorylation of GluR 1 and ERK1/2 is attenuated in DARPP-32-null mice}

Previous studies have indicated that DARPP-32 is implicated in dopamine $\mathrm{D}_{1}$ receptor-mediated phosphorylation of GluR1 (Snyder et al., 2000) and ERK1/2 (Valjent et al., 2005). Therefore, we examined the possible involvement of DARPP-32 in the increase in GluR1 and ERK1/2 phosphorylation produced by L-DOPA in 6-OHDA-lesioned mice. Wild-type and DARPP-32 knock-out mice were lesioned with 6-OHDA and treated for $10 \mathrm{~d}$ with $20 \mathrm{mg} / \mathrm{kg}$ L-DOPA. The animals were then killed $30 \mathrm{~min}$ after the last administration of L-DOPA and the levels of phospho-Ser845-GluR1 and phospho-Thr202/Tyr204-ERK1/2 were determined in striatal extracts. As shown in Figure 5, we found that the ability of L-DOPA to increase phosphorylation of GluR1 and ERK1/2 was reduced in DARPP-32-null mice compared with wild-type mice.

$\leftarrow$

immunoreactivity. $\boldsymbol{f}$ - $\boldsymbol{h}$, Immunocytochemical detection of phospho-Thr202/Tyr204-ERK (PERK) in the dorsal striata of sham-lesioned mice treated with vehicle (Sham) (f) and of 6-OHDAlesioned mice treated with L-DOPA showing low (L Dys) $(\boldsymbol{g})$ and high (H Dys) (h) dyskinesia. Scale bar, $40 \mu \mathrm{m}$. 
a

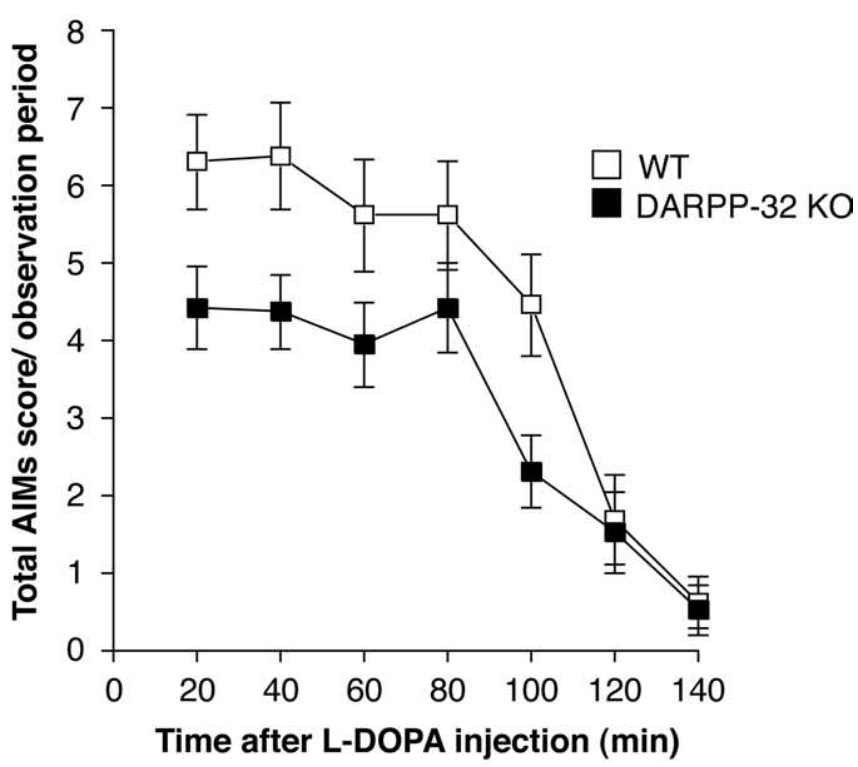

b
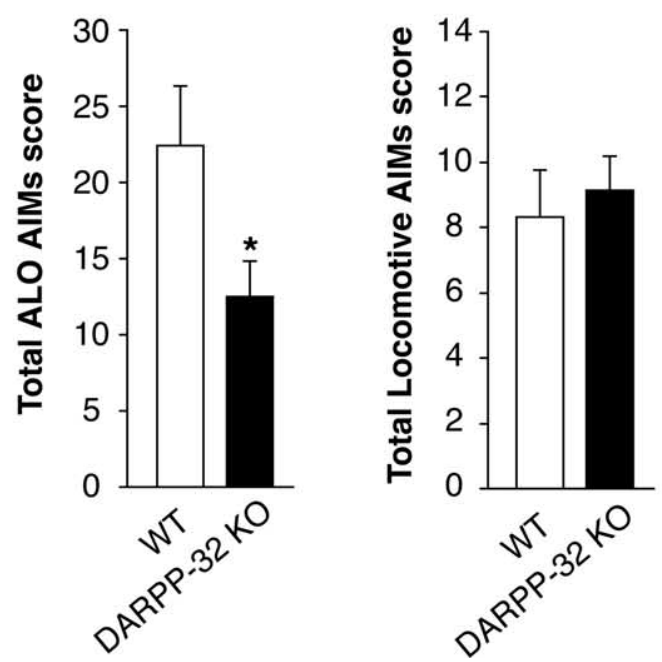

Figure 4. LID is attenuated in DARPP-32 knock-out mice. Wild-type (WT) and DARPP-32 knock-out (DARPP-32 KO) mice received unilateral injections of 6-OHDA (see Materials and Methods) and were treated for $10 \mathrm{~d}$ with $20 \mathrm{mg} / \mathrm{kg} \mathrm{L-DOPA} \mathrm{combined} \mathrm{with} 12 \mathrm{mg} / \mathrm{kg}$ benserazide. $\boldsymbol{a}$, Time profile of total axial, limb, orolingual, and locomotive AIMs scored every $20 \mathrm{~min}$ over a period of 140 min after the last drug administration. $\boldsymbol{b}$, Sum of total axial, limb, and orolingual (ALO) AIMs scored during all observation periods. c, Sum of locomotive AIMs scored during all observation periods. Data are expressed as means \pm SEM $(n=13-19)$. $\boldsymbol{a}$, Repeatedmeasure ANOVA, significant effect of genotype $\left(F_{(1,180)}=4.64 ; p<0.05\right)$, time $\left(F_{(6,180)}=\right.$ $50.16 ; p<0.001)$, and genotype $\times$ time interaction $\left(F_{(6,180)}=2.47 ; p<0.05\right) . \boldsymbol{b},{ }^{*} p<0.05$ versus WT; Student's $t$ test.

\section{LID is associated with hyperphosphorylation of MSK-1 and histone $\mathrm{H} 3$}

Activation of ERK results in the sequential phosphorylation of MSK-1 (Deak et al., 1998; Brami-Cherrier et al., 2005) and histone H3 (Soloaga et al., 2003). This, in turn, leads to changes in chromatin structure and transcriptional regulation (Nowak and Corces, 2004). We therefore examined whether enhanced phos- phorylation of ERK produced by L-DOPA in mice with severe AIMs was paralleled by upregulation of phospho-MSK-1 and phospho-histone H3. Immunohistochemical analysis revealed that the increase in ERK phosphorylation observed in highly dyskinetic mice (compare with Fig. 3) was accompanied by a larger number of phospho-MSK-1-positive neurons (Fig. 6). Simple regression analysis revealed a significant correlation between phospho-MSK-1 and AIM score (Fig. 6h). Furthermore, we found that phospho-MSK-1 and phospho-ERK immunoreactivities occurred in the same neurons (Fig. $6 f$ ). Virtually identical results were obtained when phospho-Ser10-histone $\mathrm{H} 3 \mathrm{immu}-$ noreactivity was examined (Fig. 7). Histone $\mathrm{H} 3$ acetylation plays a critical role in gene transcription and has been proposed to act in synergism with phosphorylation (Nowak and Corces, 2004). We therefore examined phospho-Ser10-acetylLys14 histone H3 immunoreactivity in the dorsal striata of mice with various degrees of dyskinesia. The results indicated the existence of an association between increased number of phospho-acetylated histone H3-positive cells and AIMs (Fig. 8). Activation of ERK signaling is linked to increased protein expression. Therefore, we tested whether upregulation of the ERK cascade associated with dyskinesia was accompanied by increased transcriptional activity. Expression of c-Fos was examined in mice with various degrees of dyskinesia. A higher number of c-Fos-positive cells was found in the striata of mice affected by severe AIMs compared with mice with low dyskinesia (supplemental Fig. 2, available at www.jneurosci.org as supplemental material).

\section{Blockade of ERK phosphorylation reduces the induction of LID}

The Western blotting and immunohistochemical results described above indicate the existence of an association between increased activity along the ERK signaling cascade and intensity of AIMs produced by repeated administration of L-DOPA to 6-OHDA-lesioned mice. To establish a causal relationship between these two phenomena, we examined the effect of pharmacological blockade of ERK phosphorylation achieved with SL327, an inhibitor of MEK, on L-DOPA-induced AIMs. SL327 (75 mg/ $\mathrm{kg}$, i.p.), injected $45 \mathrm{~min}$ before administration of L-DOPA, selectively abolished L-DOPA-induced phosphorylation of ERK1/2 (phospho-ERK1 and phospho-ERK2 in L-DOPA-treated mice were reduced to $51 \pm 12$ and $76 \pm 16 \%$ of basal levels, respectively), MSK-1 (Fig. 6b), histone H3 (Fig. 7b), and acetyl-histone H3 (Fig. 8b), without affecting DARPP-32 or GluR1 phosphorylation (data not shown; cf. Pozzi et al., 2003). Blockade of MEK did not affect the motor activating properties of L-DOPA, which were determined by measuring turning behavior (6-OHDAlesioned mice treated with $20 \mathrm{mg} / \mathrm{kg} \mathrm{L}$-DOPA alone or in combination with SL327 performed $287 \pm 72$ and $217 \pm 30$ contralateral turns per hour, respectively; $p=0.4$, Student's $t$ test). Mice lesioned unilaterally with 6-OHDA were treated for $9 \mathrm{~d}$ with 20 $\mathrm{mg} / \mathrm{kg}$ L-DOPA alone or in combination with $75 \mathrm{mg} / \mathrm{kg}$ SL327. At the end of this period, mice received an injection of L-DOPA alone and were scored for AIMs. As shown in Figure 9, we found that pretreatment with SL327 produced a dramatic reduction in L-DOPA-induced axial, limb, and orolingual AIMs. We also found that combined administration of L-DOPA plus SL327 on day 10 did not produce any additional decrease in LID.

\section{Discussion}

The main conclusion of this study is that enhanced cAMP/PKA/ DARPP-32 and ERK signaling in the medium spiny neurons of the dorsal striatum is involved in the generation of LID. We also 
SHAM/ Saline

6-OHDA/ L-DOPA a

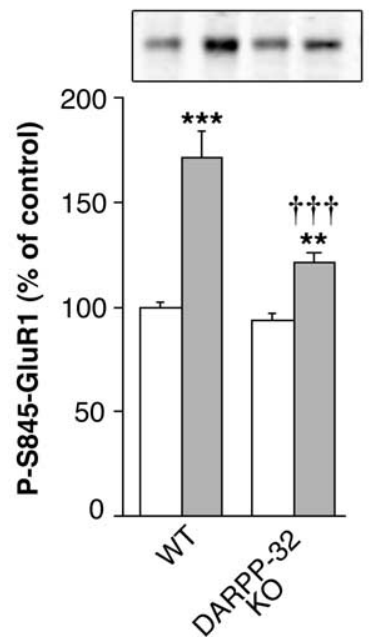

b

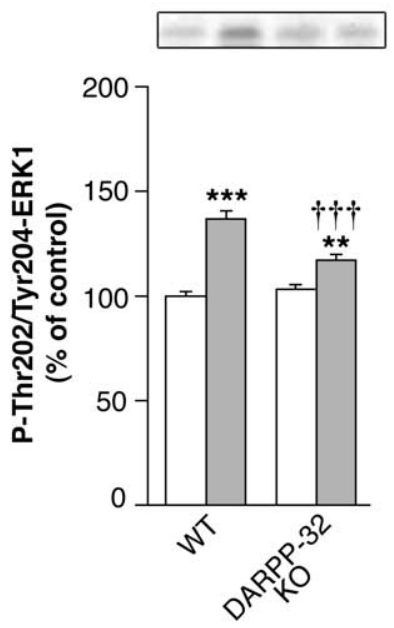

C

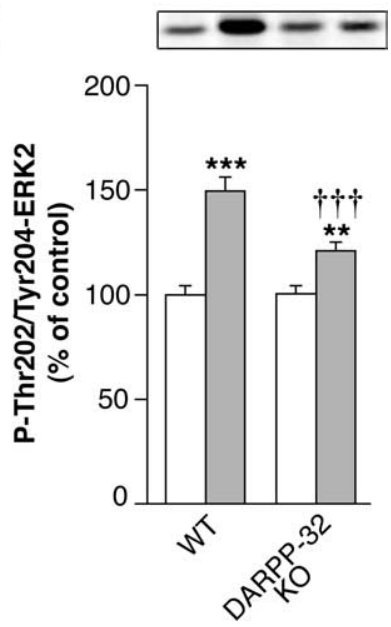

Figure 5. L-DOPA-induced phosphorylation of GluR1 and ERK1/2 is reduced in DARPP-32 knock-out mice. Sham- or 6-OHDAlesioned wild-type (WT) and DARPP-32 knock-out (DARPP-32 K0) mice were treated for $10 \mathrm{~d}$ with saline (SHAM/Saline) or L-DOPA $(20 \mathrm{mg} / \mathrm{kg})$ plus benserazide $(12 \mathrm{mg} / \mathrm{kg})(6-0 \mathrm{HDA} / \mathrm{L}-\mathrm{DOPA})$ and were killed $30 \mathrm{~min}$ after the last injection (see Materials and Methods). Phospho-Ser845-GluR1 (a), phospho-Thr202/Tyr204 -ERK1 (b), and phospho-Thr202/Tyr204 -ERK2 (c) were determined by Western blotting (see Materials and Methods). Top row shows representative autoradiograms. Bottom row shows summary of data represented as means $\pm \operatorname{SEM}(n=6-19) .{ }^{* *} p<0.01$ and ${ }^{* * *} p<0.001$ versus respective SHAM/Saline group; ${ }^{+{ }^{+\dagger}} p<0.001$ versus 6-OHDA/L-DOPA WT; two-way ANOVA, followed by Bonferroni-Dunn test. A significant interaction was found between genotype and treatment $\left(\boldsymbol{a}, F_{(1,41)}=5.24, p<0.05 ; \boldsymbol{b}, F_{(1,41)}=4.54, p<0.05 ;\right.$ and $\left.\boldsymbol{c}, F_{(1,41)}=4.96, p<0.05\right)$.

phosphorylation produced by L-DOPA in 6-OHDA-lesioned mice is reduced in the absence of DARPP-32. It therefore appears that sensitized ERK signaling produced by dopamine depletion is, at least in part, dependent on abnormal activation of the cAMP/DARPP-32 pathway.

Prolonged administration of L-DOPA to 6-OHDA-lesioned mice leads to an overall reduction in the ability of this drug to activate cAMP and ERK signaling. A similar adaptive response, affecting dopamine $\mathrm{D}_{1}$ receptor-mediated phosphorylation of ERK, has been described recently in dopamine-depleted mice subjected to repeated injections of L-DOPA (Kim et al., 2006). In the present study, however, we show that the decline in the ability of L-DOPA to promote cAMP/PKA/ DARPP-32 and ERK signaling occurs specifically in mice with low dyskinesia. In contrast, in animals affected by severe LID, the sensitized response to L-DOPA is essentially preserved. These results suggest that dyskinesia is caused by persistent upregulation of cAMP/PKA/DARPP-32 and ERK signaling, starting from the beginning of L-DOPA administration.

One important finding of this study is that the AIMs generated by repeated ad-

provide evidence demonstrating that dysregulation of these two intracellular pathways is linked and that increased activity along the ERK cascade observed in dyskinesia depends on concomitant enhancement of CAMP/PKA/DARPP-32 signaling (Fig. 10).

Administration of L-DOPA to naive mice does not affect the state of phosphorylation of DARPP-32 and GluR1. In contrast, after dopamine denervation, L-DOPA produces large increases in both phospho-Thr34-DARPP-32 and phospho-Ser845-GluR1. These changes in responsiveness are most likely attributable to enhanced sensitivity of dopamine $\mathrm{D}_{1}$ receptors. Increased expression of $G_{\text {olf }}$-protein, suggesting augmented dopamine $D_{1}$ receptor-mediated transmission, has been described in the striata of 6-OHDA-lesioned rats and in postmortem samples from parkinsonian patients (Corvol et al., 2004) and was also observed in our study (data not shown). Furthermore, enhanced $D_{1}$ receptor-G-protein coupling has been reported in the striata of MPTP-lesioned dyskinetic monkeys (Aubert et al., 2005). Because $\mathrm{G}_{\text {olf }}$-protein is coupled to stimulation of cAMP signaling, it is conceivable that increased $\mathrm{G}_{\text {olf }}$ expression/coupling is responsible for the PKA-dependent hyperphosphorylation of DARPP-32 and GluR1 reported here in hemiparkinsonian mice.

It has been shown that striatal dopamine depletion confers to a dopamine $D_{1}$ receptor agonist the ability to stimulate ERK phosphorylation (Gerfen et al., 2002; Kim et al., 2006). In line with this evidence, we found that administration of L-DOPA increases ERK1/2 phosphorylation in 6-OHDA-lesioned but not in naive mice. Recent work has shown that activation of the cAMP/ DARPP-32 cascade mediates the ability of cocaine and amphetamine (two drugs that promote dopamine release) to stimulate ERK phosphorylation (Valjent et al., 2005). The present study reveals the existence of a similar interaction between cAMP and ERK signaling with respect to the action of L-DOPA in the dopamine-denervated striatum. Thus, the increase in ERK1/2 ministration of L-DOPA are reduced in DARPP-32-deficient mice. This reduction appears to affect specifically axial, limb, and orolingual AIMs, whereas locomotive AIMs are virtually unaffected. In this regard, it should be mentioned that axial, limb, and orolingual AIMs are generally regarded as a more predictive marker of LID, because they are associated with molecular changes occurring in the dorsolateral portion of the striatal formation, which is specifically innervated by nigrostriatal fibers (Andersson et al., 1999).

Phosphorylation of Thr34 significantly correlates with the degree of dyskinesia and mediates the increases in GluR1 and ERK phosphorylation associated with LID. Thus, in the dopaminedenervated striatum, phospho-Thr34-DARPP-32 acts as an important mechanism able to exacerbate enhanced cAMP and ERK signaling in response to L-DOPA administration. The lack of such DARPP-32-mediated amplification may therefore result in a partial normalization of cAMP/PKA and ERK signaling, ultimately leading to the attenuation of the dyskinetic response.

The reduction of LID observed in DARPP-32-null mice may be in part attributable to reduced phosphorylation of GluR1 receptors. Previous studies have demonstrated the ability of DARPP-32 to intensify PKA-dependent phosphorylation of GluR1 via inhibition of PP-1-mediated dephosphorylation (Snyder et al., 2000; Håkansson et al., 2006). It is generally assumed that phosphorylation at Ser845 promotes glutamate AMPA receptor transmission by increasing open AMPA channel probability (Banke et al., 2000) and surface expression (Mangiavacchi and Wolf, 2004). Augmented AMPA receptor transmission may be involved in dyskinesia, as suggested by the ability of an AMPA receptor agonist to increase LID in the MPTP-lesioned primate model (Konitsiotis et al., 2000). Moreover, blockade of AMPA receptors results in a significant attenuation of LID (Konitsiotis et al., 2000). The blunted dyskinetic response observed in 


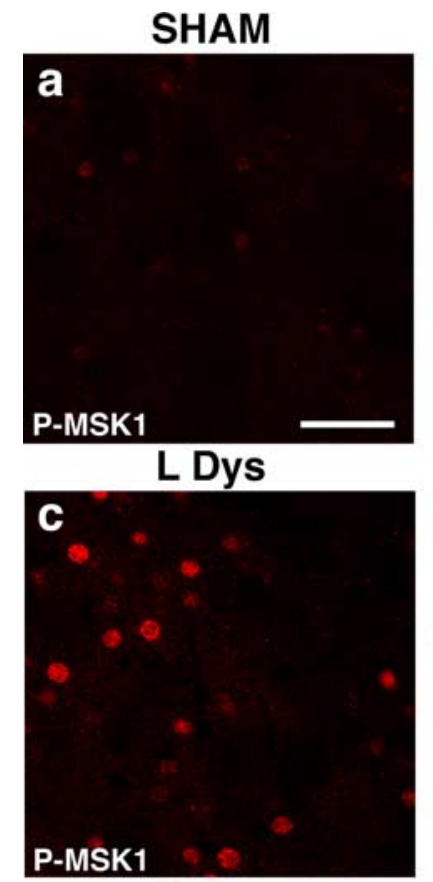

H Dys

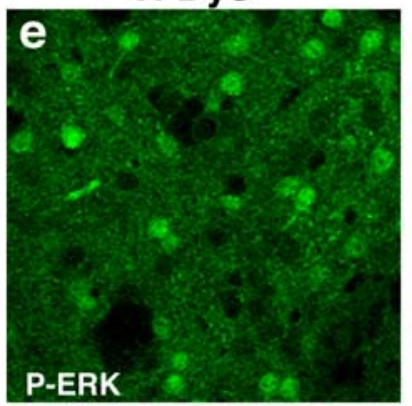

g

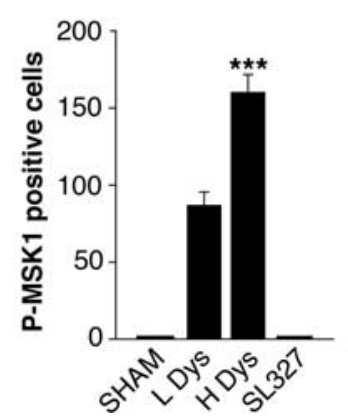

SL327

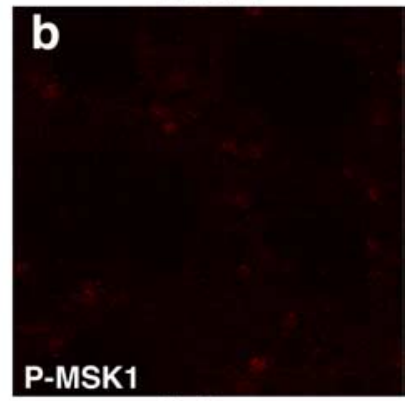

H Dys

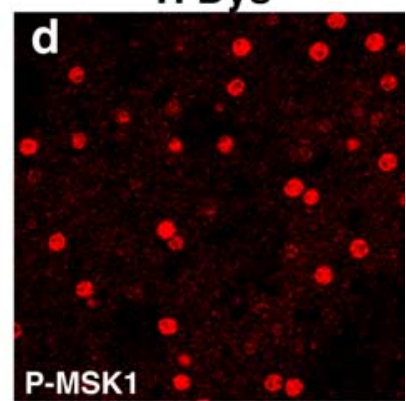

H Dys

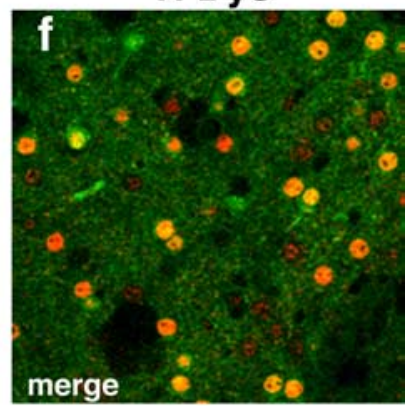

h

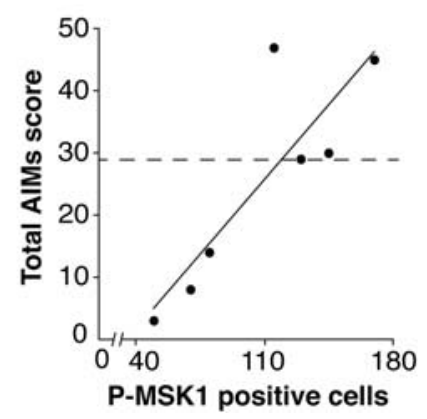

Figure 6. Phosphorylation of MSK-1 is associated with LID. $\boldsymbol{a}-\boldsymbol{d}$, Immunocytochemical detection of phospho-Thr581-MSK-1 (P-MSK1) in sham-lesioned mouse treated with vehicle ( $\boldsymbol{a}$; SHAM), 6-OHDA-lesioned mouse treated with L-DOPA (20 mg/kg) in combination with SL327 (b; SL327) (75 mg/kg), 6-OHDA-lesioned mouse with low dyskinesia (c; L Dys), and 6-OHDAlesioned mouse with high dyskinesia ( $\boldsymbol{d}$; $\mathrm{H}$ Dys). Note the abolishment of phospho-MSK-1 immunoreactivity in $\boldsymbol{b}$ compared with c and $\boldsymbol{d}$. $\boldsymbol{e}$, Phospho-Thr202/Tyr204 -ERK (P-ERK) immunoreactivity in the dorsal striatum of a mouse with high dyskinesia. $f$, Double immunolabeling showing colocalization between phospho-ERK and phospho-MSK-1 in a mouse with high dyskinesia. g, 6-OHDA-lesioned mice were divided into low dyskinetic (L Dys) and high dyskinetic (HDys) according to their total AIM score (see Materials and Methods) using the median value of 29 as cutoff. Histograms show the number of phospho-MSK-1-positive cells in the dorsal striata of sham-lesioned mice (SHAM), mice with low (LDys) and high (HDys) dyskinesia, and 6-OHDAlesioned mice treated with L-DOPA in combination with SL327 $(75 \mathrm{mg} / \mathrm{kg})(\mathrm{SL327})$. Data are means \pm SEM $(n=3-7)$. ${ }^{* *} p<0.001$ versus L Dys; one-way ANOVA, followed by BonferroniDunn test. $\boldsymbol{h}$, Simple regression analysis showing significant correlation $(r=0.858 ; p<0.05)$ between the number of phospho-MSK-1-positive cells and AIM score. Scale bar: $\boldsymbol{a}-\boldsymbol{f}, 40 \mu \mathrm{m}$.
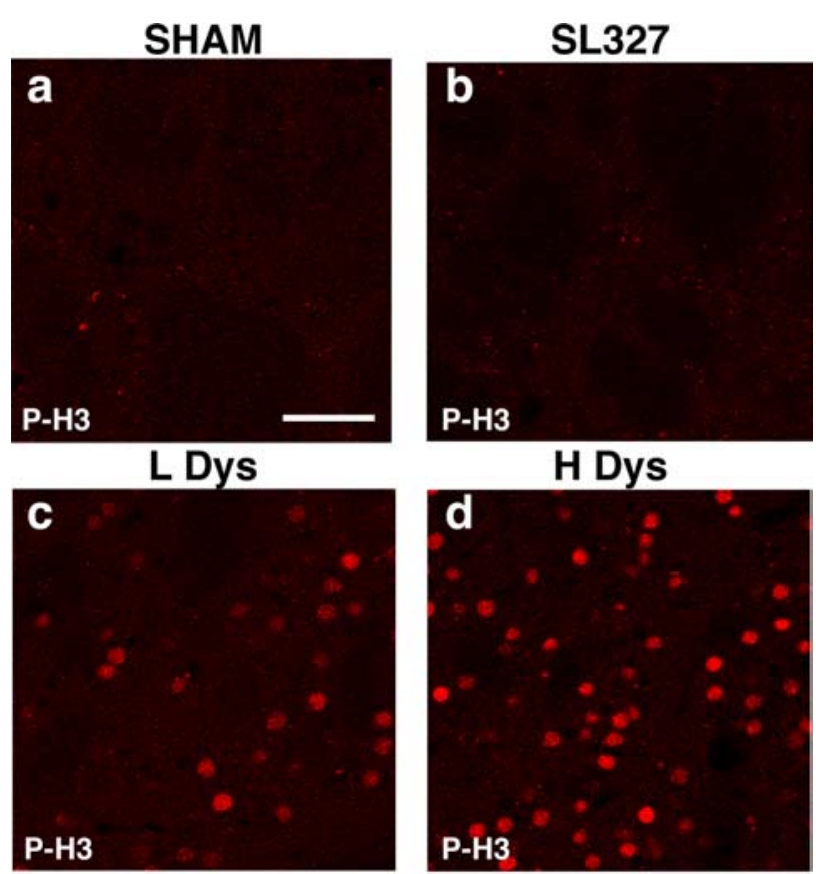

H Dys

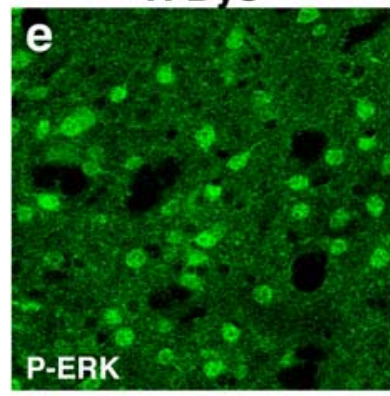

\section{g}
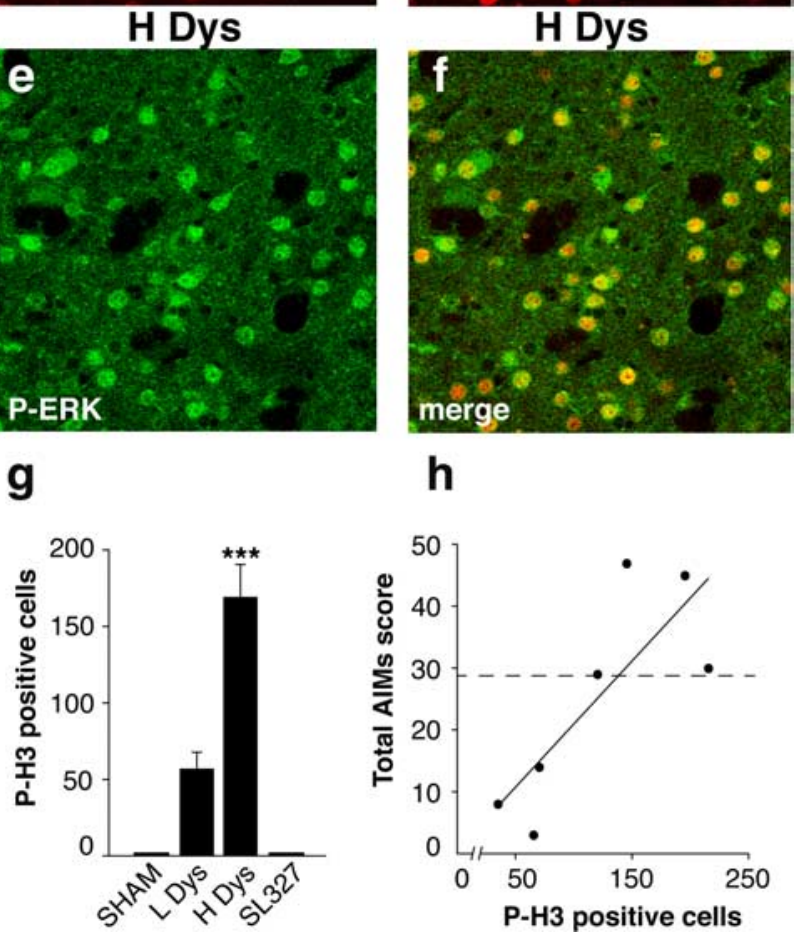

h

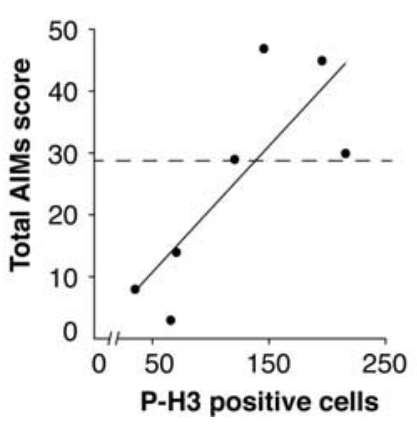

Figure 7. Phosphorylation of histone $\mathrm{H} 3$ is associated with LID. $\boldsymbol{a}-\boldsymbol{d}$, Immunocytochemical detection of phospho-Ser10 - histone $\mathrm{H3}$ ( $\mathrm{P}-\mathrm{H} 3$ ) in sham-lesioned mouse treated with vehicle (a; Sham), 6-OHDA-lesioned mouse treated with L-DOPA (20 mg/kg) in combination with SL 327 $(75 \mathrm{mg} / \mathrm{kg})(\boldsymbol{b} ;$ SL327), 6-OHDA-lesioned mouse with low dyskinesia ( $\boldsymbol{c}$; L Dys), and 6-OHDAlesioned mouse with high dyskinesia (d; H Dys). Note the abolishment of phospho-Ser10histone $\mathrm{H} 3$ immunoreactivity in $\boldsymbol{b}$ compared with $\boldsymbol{c}$ and $\boldsymbol{d}$. $\boldsymbol{e}$, Phospho-Thr202/Tyr204-ERK (P-ERK) immunoreactivity in the dorsal striatum of a mouse with high dyskinesia. $\boldsymbol{f}$, Double immunolabeling showing colocalization between Phospho-Thr202/Tyr204 -ERK and phosphoSer10 - histone H3 in a mouse with high dyskinesia. g, 6-OHDA-lesioned mice were divided into low dyskinetic (L Dys) and high dyskinetic (H Dys) according to their total AIM score (see Materials and Methods) using the median value of 29 as cutoff. Histograms show the number of phospho-Ser10 - histone H3-positive cells in the dorsal striata of sham-lesioned mice (SHAM), mice with low (L Dys) and high (H Dys) dyskinesia, and 6-OHDA-lesioned mice treated with L-DOPA in combination with SL327 (75 mg/kg) (SL327). Data are means \pm SEM $(n=3-7)$. ${ }^{* * *} p<0.001$ versus $L$ Dys; one-way ANOVA, followed by Bonferroni-Dunn test. $\boldsymbol{h}$, Simple regression analysis showing significant correlation $(r=0.803 ; p<0.05)$ between the number of phospho-Ser10 - histone H3-positive cells and AIM score. Scale bar: $\boldsymbol{a}-\boldsymbol{f}, 40 \mu \mathrm{m}$. 

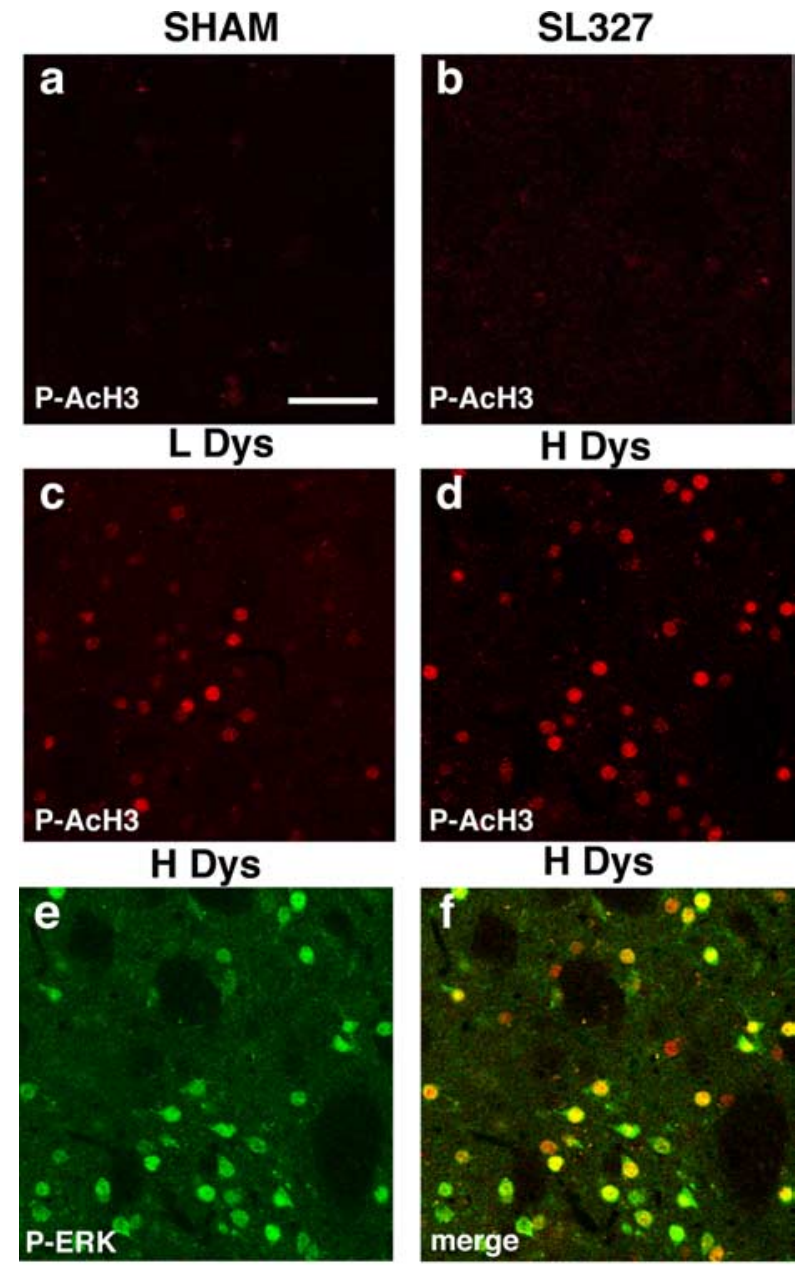

\section{g}

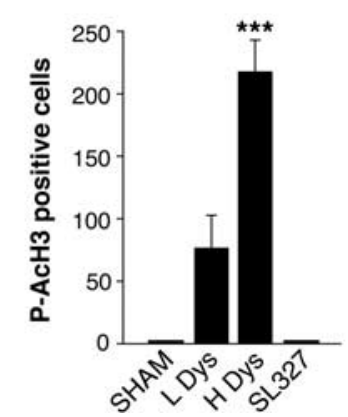

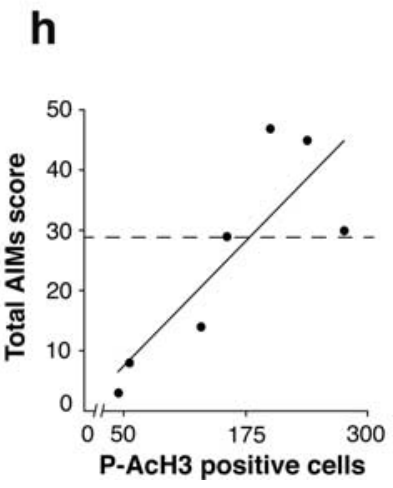

Figure 8. Phosphorylation of acetyl-histone $\mathrm{H} 3$ is associated with LID. $\boldsymbol{a}-\boldsymbol{d}$, Immunocytochemical detection of phospho-Ser10-acetylLys14 histone $\mathrm{H3}$ ( $\mathrm{P}-\mathrm{AcH} 3)$ in sham-lesioned mouse treated with vehicle ( $\boldsymbol{a}$; SHAM), 6-OHDA-lesioned mouse treated with L-DOPA (20 mg/ $\mathrm{kg}$ ) in combination with SL327 (75 mg/kg) (b; SL327), 6-0HDA-lesioned mouse with low dyskinesia ( $\boldsymbol{c}$; L Dys), and 6-OHDA-lesioned mouse with high dyskinesia (d; H Dys). Note the abolishment of phospho-Ser10-acetylLys14 histone H3 immunoreactivity in $\boldsymbol{b}$ compared with $\boldsymbol{c}$ and $\boldsymbol{d}$. $\boldsymbol{e}$, Phospho-Thr202/Tyr204-ERK (P-ERK) immunoreactivity in the dorsal striatum of a mouse with high dyskinesia. $f$, Double immunolabeling showing colocalization between Phospho-Thr202/Tyr204 -ERK and phospho-Ser10 -acetylLys14 histone H3 in a mouse with H Dys. g, 6-OHDA-lesioned mice were divided into low dyskinetic (L Dys) and high dyskinetic (H Dys) according to their total AIMs score (see Materials and Methods) using the median value of 29 as cutoff. Histograms show the number of phospho-Ser10-acetylLys14 histone H3-positive cells in the dorsal striata of sham-lesioned mice (SHAM), mice with low (L Dys) and high (H Dys) dyskinesia, and 6-OHDA-lesioned mice treated with L-DOPA in combination with SL327 (75 $\mathrm{mg} / \mathrm{kg})(\mathrm{SL} 327)$. Data are means \pm SEM $(n=3-7)$. ${ }^{* * *} p<0.001$ versus L Dys; one-way ANOVA, followed by Bonferroni-Dunn test. $\boldsymbol{h}$, Simple regression analysis showing significant correlation $(r=0.835 ; p<0.05$ ) between the number of phospho-Ser10 -acetyllys 14 histone $\mathrm{H} 3$-positive cells and AIM score. Scale bar: $\boldsymbol{a}-\boldsymbol{f}, 40 \mu \mathrm{m}$.

a
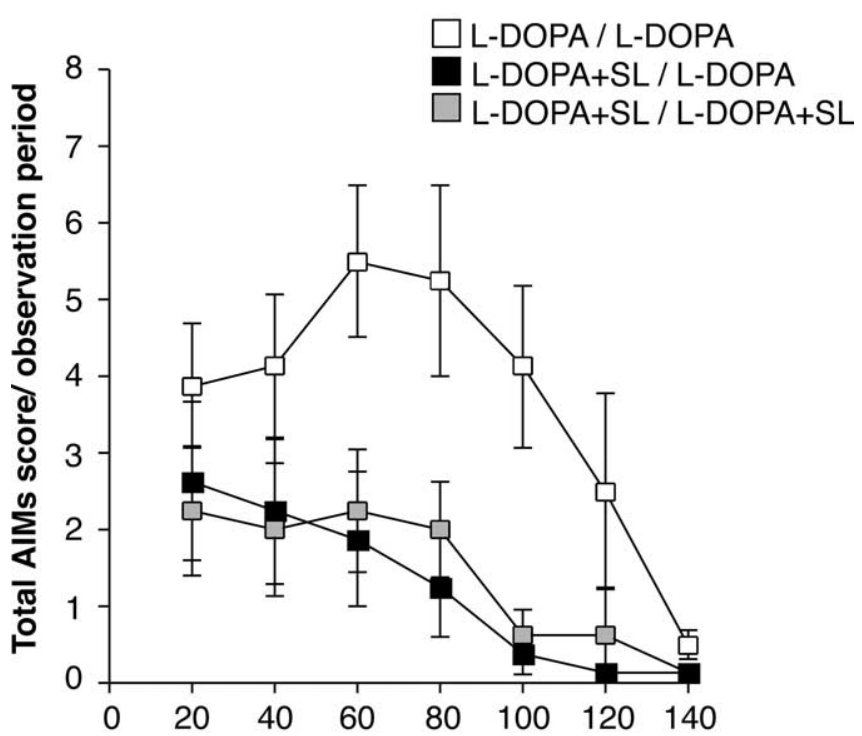

Time after L-DOPA injection (min) b

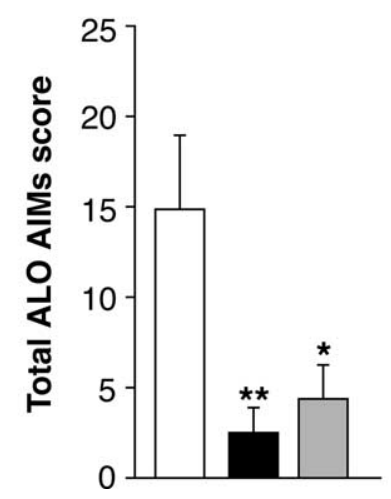

\section{C}

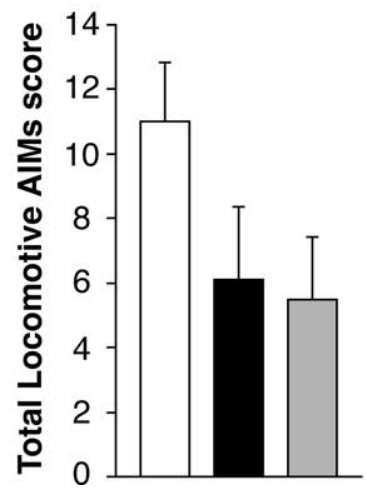

Figure 9. Pretreatment with SL327 reduces LID. 6-0HDA-lesioned mice were treated for $9 \mathrm{~d}$ with $20 \mathrm{mg} / \mathrm{kg}$ L-DOPA alone (white symbols) or in combination with SL327 (75 mg/kg) (SL; black and gray symbols). At the end of this period, AIMs were determined after administration of L-DOPA alone (open and black symbols) or L-DOPA plus SL327 (gray symbols). $\boldsymbol{a}$, Time profile of total axial, limb, orolingual, and locomotive AIMs scored every 20 min over a period of 140 min after the last drug administration. $\boldsymbol{b}$, Sum of total axial, limb, and orolingual (ALO) AIMs scored during all observation periods. $c$, Sum of locomotive AIMs scored during all observation periods. Data are expressed as means $\pm \operatorname{SEM}(n=8) . \boldsymbol{a}$, Repeated-measure ANOVA, significant effect of SL327 treatment $\left(F_{(2,126)}=4.59 ; p<0.05\right)$, time $\left(F_{(6,126)}=14.95 ; p<0.001\right)$, and SL327 treatment $\times$ time interaction $\left(F_{(12,126)}=2.23 ; p<0.05\right) \cdot \boldsymbol{b},{ }^{*} p<0.05$ and ${ }^{* *} p<0.01$ versus L-DOPA/L-DOPA group; one-way ANOVA, followed by Bonferroni-Dunn test.

DARPP-32 knock-out mice may therefore be attributable, at least in part, to decreased phosphorylation and consequent reduced activation of GluR1 AMPA receptors.

It has been shown that long-term depression is accompanied by a rapid decrease in the number of AMPA receptors clustered at the synapse (Carroll et al., 1999). This effect may be opposed by phosphorylation of GluR1 at Ser845, which increases surface expression of AMPA receptors (Mangiavacchi and Wolf, 2004). Through this mechanism, the high levels of phospho-Ser845GluR1 detected in the striata of dyskinetic mice may explain previous data showing that LID is accompanied by the inability of 
corticostrial synapses to undergo depotentiation (Picconi et al., 2003).

The reduction of LID observed in DARPP-32 knock-out mice was also accompanied by attenuation of L-DOPAinduced ERK1/2 phosphorylation. This observation, together with the existence of a high correlation between AIM severity and levels of phosphorylated ERK, prompted us to examine the possible involvement of these mitogen-activated protein kinases in the generation of LID. We found that blockade of ERK phosphorylation, achieved by administration of SL327 in combination with L-DOPA, resulted in a remarkable decrease in AIMs. This effect could not be attributed to a general depression in motor activity produced by the MEK inhibitor, because SL327 did not affect L-DOPA-induced contralateral turning. Furthermore, and most importantly, SL327 was administered with L-DOPA only during the $9 \mathrm{~d}$ preceding the determination of AIMs. The attenuation of LID produced by pharmacological blockade of ERK was larger than that observed in DARPP-32 knock-out mice. This higher efficacy in counteracting LID may be attributable to the fact that SL327 produced a complete abolishment of L-DOPAinduced ERK phosphorylation compared with the partial blockade observed in DARPP-32-null mice.

The ability of ERK to regulate gene transcription depends on the sequential phosphorylation of downstream targets, ultimately responsible for changes in protein expression. In this study, we examined the state of phosphorylation of MSK-1, which is directly controlled by ERK (Deak et al., 1998). Immunohistochemical analysis revealed a significant correlation between the number of phospho-MSK-1positive neurons detected in the dorsal striatum and the severity of AIMs. Previous work has shown the importance of MSK-1 in the phosphorylation/activation of histone H3 (Soloaga et al., 2003) and cocaine-induced c-Fos expression (BramiCherrier et al., 2005). In line with these observations, we found that increased MSK-1 phosphorylation observed in dyskinesia is paralleled by concomitant increases in the levels of phosphorylated and phospho-acetylated histone $\mathrm{H} 3$ and of c-Fos immunoreactivity. Whereas a direct demonstration of the involvement of MSK-1 in the motor side effects of L-DOPA will require additional studies, it is interesting to note that this protein has been implicated recently in psychomotor sensitization produced by cocaine, a drug that promotes dopaminergic transmission by increasing neurotransmitter release (BramiCherrier et al., 2005).

The data presented in this study indicate that the ability of SL327 to counteract LID is attributable to blockade of long-term processes occurring in striatal medium spiny neurons and prob- ably related to the involvement of ERK in transcriptional or translational control. However, we cannot exclude that SL327 may also reduce dyskinesia by interfering with short-term regulation of cytoplasmic or membrane proteins. The present study indicates that the long-term effects produced by SL327 occlude possible short-term action of this drug. Additional studies will be necessary to identify specific targets controlled by ERK that may be responsible for a short-term antidyskinetic action of SL327.

In conclusion, this study provides the first evidence of a critical role played by sensitized CAMP/PKA/DARPP-32 and ERK signaling in L-DOPA-induced AIMs. The data presented indicate that a significant fraction of LID is generated by a persistent sensitized response to L-DOPA, involving upregulation of cAMP/ 
PKA/phospho-Thr34-DARPP-32-mediated signaling, activation of ERK1/2, increased phosphorylation of MSK-1, and increased phosphorylation of acetylated histone H3 (Fig. 10). This, in turn, may lead to changes in protein expression and long-term modification of the functional features of striatal medium spiny neurons. The present results also suggest that therapeutic strategies based on attenuation of ERK signaling in the dorsal striatum may represent a novel clinical approach to the prevention of LID.

\section{References}

Andersson M, Hilbertson A, Cenci MA (1999) Striatal fosB expression is causally linked with L-DOPA-induced abnormal involuntary movements and the associated upregulation of striatal prodynorphin mRNA in a rat model of Parkinson's disease. Neurobiol Dis 6:461-474.

Aubert I, Guigoni C, Hakansson K, Li Q, Dovero S, Barthe N, Bioulac BH, Gross CE, Fisone G, Bloch B, Bezard E (2005) Increased D1 dopamine receptor signaling in levodopa-induced dyskinesia. Ann Neurol 57:17-26.

Banke TG, Bowie D, Lee H, Huganir RL, Schousboe A, Traynelis SF (2000) Control of GluR1 AMPA receptor function by cAMP-dependent protein kinase. J Neurosci 20:89-102.

Brami-Cherrier K, Valjent E, Herve D, Darragh J, Corvol JC, Pages C, Arthur SJ, Girault JA, Caboche J (2005) Parsing molecular and behavioral effects of cocaine in mitogen- and stress-activated protein kinase-1deficient mice. J Neurosci 25:11444-11454.

Brotchie JM, Lee J, Venderova K (2005) Levodopa-induced dyskinesia in Parkinson's disease. J Neural Transm 112:359-391.

Carroll RC, Lissin DV, von Zastrow M, Nicoll RA, Malenka RC (1999) Rapid redistribution of glutamate receptors contributes to long-term depression in hippocampal cultures. Nat Neurosci 2:454-460.

Corvol JC, Studler JM, Schonn JS, Girault JA, Herve D (2001) Galpha(olf) is necessary for coupling D1 and A2a receptors to adenylyl cyclase in the striatum. J Neurochem 76:1585-1588.

Corvol JC, Muriel MP, Valjent E, Feger J, Hanoun N, Girault JA, Hirsch EC, Herve D (2004) Persistent increase in olfactory type G-protein $\alpha$ subunit levels may underlie $\mathrm{D}_{1}$ receptor functional hypersensitivity in Parkinson disease. J Neurosci 24:7007-7014.

Deak M, Clifton AD, Lucocq LM, Alessi DR (1998) Mitogen- and stressactivated protein kinase-1 (MSK1) is directly activated by MAPK and SAPK2/ p38, and may mediate activation of CREB. EMBO J 17:4426-4441.

Fienberg AA, Hiroi N, Mermelstein PG, Song W, Snyder GL, Nishi A, Cheramy A, O'Callaghan JP, Miller DB, Cole DG, Corbett R, Haile CN, Cooper DC, Onn SP, Grace AA, Ouimet CC, White FJ, Hyman SE, Surmeier DJ, Girault J, Nestler EJ, Greengard P (1998) DARPP-32: regulator of the efficacy of dopaminergic neurotransmission. Science 281:838-842.

Gerfen CR, Miyachi S, Paletzki R, Brown P (2002) D dopamine receptor supersensitivity in the dopamine-depleted striatum results from a switch in the regulation of ERK1/2/MAP kinase. J Neurosci 22:5042-5054.

Håkansson K, Galdi S, Hendrick J, Snyder G, Greengard P, Fisone G (2006) Regulation of phosphorylation of the GluR1 AMPA receptor by dopamine D2 receptors. J Neurochem 96:482-488.

Hemmings Jr HC, Greengard P (1986) DARPP-32, a dopamine- and adenosine $3^{\prime}: 5^{\prime}$-monophosphate-regulated phosphoprotein: regional, tissue, and phylogenetic distribution. J Neurosci 6:1469-1481.

Hemmings Jr HC, Greengard P, Tung HY, Cohen P (1984) DARPP-32, a dopamine-regulated neuronal phosphoprotein, is a potent inhibitor of protein phosphatase-1. Nature 310:503-505.

Kim DS, Palmiter RD, Cummins A, Gerfen CR (2006) Reversal of supersensitive striatal dopamine D1 receptor signaling and extracellular signalregulated kinase activity in dopamine-deficient mice. Neuroscience 137:1381-1388.

Konitsiotis S, Blanchet PJ, Verhagen L, Lamers E, Chase TN (2000) AMPA receptor blockade improves levodopa-induced dyskinesia in MPTP monkeys. Neurology 54:1589-1595.

Lundblad M, Picconi B, Lindgren H, Cenci MA (2004) A model of L-DOPAinduced dyskinesia in 6-hydroxydopamine lesioned mice: relation to motor and cellular parameters of nigrostriatal function. Neurobiol Dis $16: 110-123$.
Lundblad M, Usiello A, Carta M, Hakansson K, Fisone G, Cenci MA (2005) Pharmacological validation of a mouse model of L-DOPA-induced dyskinesia. Exp Neurol 194:66-75.

Mammen AL, Kameyama K, Roche KW, Huganir RL (1997) Phosphorylation of the alpha-amino-3-hydroxy-5-methylisoxazole4-propionic acid receptor GluR1 subunit by calcium/calmodulin-dependent kinase II. J Biol Chem 272:32528-32533.

Mangiavacchi S, Wolf ME (2004) D1 dopamine receptor stimulation increases the rate of AMPA receptor insertion onto the surface of cultured nucleus accumbens neurons through a pathway dependent on protein kinase A. J Neurochem 88:1261-1271.

Nishi A, Snyder GL, Greengard P (1997) Bidirectional regulation of DARPP-32 phosphorylation by dopamine. J Neurosci 17:8147-8155.

Nowak SJ, Corces VG (2004) Phosphorylation of histone H3: a balancing act between chromosome condensation and transcriptional activation. Trends Genet 20:214-220.

Obeso JA, Olanow CW, Nutt JG (2000) Levodopa motor complications in Parkinson's disease. Trends Neurosci 23:S2-S7.

Pavon N, Martin AB, Mendialdua A, Moratalla R (2006) ERK phosphorylation and FosB expression are associated with L-DOPA-induced dyskinesia in hemiparkinsonian mice. Biol Psychiatry 59:64-74.

Paxinos G, Watson C (1982) The rat brain in stereotaxic coordinates. New York: Academic.

Picconi B, Centonze D, Hakansson K, Bernardi G, Greengard P, Fisone G, Cenci MA, Calabresi P (2003) Loss of bidirectional striatal synaptic plasticity in L-DOPA-induced dyskinesia. Nat Neurosci 6:501-506.

Pozzi L, Håkansson K, Usiello A, Borgkvist A, Lindskog M, Greengard P, Fisone G (2003) Opposite regulation by typical and atypical antipsychotics of ERK1/2, CREB and Elk-1 phosphorylation in mouse dorsal striatum. J Neurochem 86:451-459.

Roche KW, O’Brien RJ, Mammen AL, Bernhardt J, Huganir RL (1996) Characterization of multiple phosphorylation sites on the AMPA receptor GluR1 subunit. Neuron 16:1179-1188.

Schallert T, Tillerson JL (2000) Intervention strategies for degeneration of dopamine neurons in parkinsonism: optimizing behavioral assessment of outcome. In: Central nervous system diseases: innovative models of CNS diseases from molecule to therapy (Emerich DF, Dean III RL, Sanberg PR, eds), pp 131-151. Totowa, NJ: Humana.

Snyder GL, Girault JA, Chen JY, Czernik AJ, Kebabian JW, Nathanson JA, Greengard P (1992) Phosphorylation of DARPP-32 and protein phosphatase inhibitor-1 in rat choroid plexus: regulation by factors other than dopamine. J Neurosci 12:3071-3083.

Snyder GL, Allen PB, Fienberg AA, Valle CG, Huganir RL, Nairn AC, Greengard P (2000) Regulation of phosphorylation of the GluR1 AMPA receptor in the neostriatum by dopamine and psychostimulants in vivo. J Neurosci 20:4480-4488.

Soloaga A, Thomson S, Wiggin GR, Rampersaud N, Dyson MH, Hazzalin CA, Mahadevan LC, Arthur JS (2003) MSK2 and MSK1 mediate the mitogen- and stress-induced phosphorylation of histone H3 and HMG14. ЕMBO J 22:2788-2797.

Svenningsson P, Lindskog M, Ledent C, Parmentier M, Greengard P, Fredholm BB, Fisone G (2000) Regulation of the phosphorylation of the dopamine- and cAMP-regulated phosphoprotein of $32 \mathrm{kDa}$ in vivo by dopamine D1, dopamine D2, and adenosine A2A receptors. Proc Natl Acad Sci USA 97:1856-1860.

Sweatt JD (2004) Mitogen-activated protein kinases in synaptic plasticity and memory. Curr Opin Neurobiol 14:311-317.

Thomas GM, Huganir RL (2004) MAPK cascade signalling and synaptic plasticity. Nat Rev Neurosci 5:173-183.

Towbin H, Staehelin T, Gordon J (1979) Electrophoretic transfer of proteins from polyacrylamide gels to nitrocellulose sheets: procedure and some applications. Proc Natl Acad Sci USA 76:4350-4354.

Valjent E, Pascoli V, Svenningsson P, Paul S, Enslen H, Corvol JC, Stipanovich A, Caboche J, Lombroso PJ, Nairn AC, Greengard P, Herve D, Girault JA (2005) Regulation of a protein phosphatase cascade allows convergent dopamine and glutamate signals to activate ERK in the striatum. Proc Natl Acad Sci USA 102:491-496.

Zhuang X, Belluscio L, Hen R (2000) $\mathrm{G}_{\text {olf } \alpha}$ mediates dopamine $\mathrm{D}_{1}$ receptor signaling. J Neurosci 20:RC91(1-5). 